\title{
EXPLORATION OF IOCG MINERALIZATIONS USING INTEGRATION OF SPACE- BORNE REMOTE SENSING DATA WITH AIRBORNE GEOPHYSICAL DATA
}

\author{
M. Abdolmaleki ${ }^{1, *}$, T.M. Rasmussen ${ }^{1}$, M.K. Pal ${ }^{1}$ \\ ${ }^{1}$ Division of Geosciences and Environmental Engineering, Department of Civil, Environmental and Natural Resources \\ Engineering, Luleå University of Technology, Luleå-971 87, Norrbotten county, Sweden - (mehdi.abdolmaleki; \\ thorkild.maack.rasmussen; mahendra.pal)@1tu.se
}

\section{Commission III/1}

KEY WORDS: Sentinel-2, airborne geophysics, IOCG mineralisation, Greenland

\begin{abstract}
:
Nowadays, remote sensing technologies are playing a significant role in mineral potential mapping. To optimize the exploration approach along with a cost-effective way, narrow down the target areas for a more detailed study for mineral exploration using suitable data selection and accurate data processing approaches are crucial. To establish optimum procedures by integrating space-borne remote sensing data with other earth sciences data (e.g., airborne magnetic and electromagnetic) for exploration of Iron Oxide Copper Gold (IOCG) mineralization is the objective of this study. Further, the project focus is to test the effectiveness of Copernicus Sentinel-2 data in mineral potential mapping from the high Arctic region. Thus, Inglefield Land from northwest Greenland has been chosen as a study area to evaluate the developed approach. The altered minerals, including irons and clays, were mapped utilizing Sentinel-2 data through band ratio and principal component analysis (PCA) methods. Lineaments of the study area were extracted from Sentinel-2 data using directional filters. Self-Organizing Maps (SOM) and Support Vector Machines (SVM) were used for classification and analysing the available data. Further, various thematic maps (e.g., geological, geophysical, geochemical) were prepared from the study area. Finally, a mineral prospectively map was generated by integrating the above mentioned information using the Fuzzy Analytic Hierarchy Process (FAHP). The prepared potential map for IOCG mineralization using the above approach of Inglefield Land shows a good agreement with the previous geological field studies.
\end{abstract}

\section{INTRODUCTION}

\subsection{Mineral exploration}

Mineral exploration is performed with the objective of finding ore deposits in commercially viable concentrations and is often a sequential process of information gathering and interpretation. Finding the ore deposits is one of the most challenging and costly tasks for the mining industries. Mineral exploration is in general very costly in terms of average investment return rate. In particular, the search in frontier regions of large extent is often associated with significant costs and uncertainties. Geophysical, geochemical and geological field work and associated data processing and interpretation constitute major parts of the expenses prior to any decision on drilling and mining activities. Satellite based remote sensing data may provide information for planning of more optimised field work as well as aid the interpretations. Nowadays, availability of various remote sensing datasets (e.g., NASA's Landsat series (1-8) and ASTER, ESA's Sentinel series (1 to 5)) with low or no cost are playing key role to narrow down and target the potential areas in mineral exploration.

This study is focusing on the use of Copernicus Sentinel-2 data for mineral exploration. Details on the Sentinel-2 system can be found in Drusch et al. (2012). Mineral alteration mapping (iron oxide \& hydroxide minerals) and lineament mapping is performed for data from Inglefield Land, northwest Greenland. The interpretations involve integration of the remote sensing data with airborne geophysical data.

\subsection{IOCG deposits}

After the discovery of the Olympic Dam Cu-U-Au-Ag-REE deposit in South Australia in 1975, a new conception of an important class of ore deposits referred as Iron Oxide Copper Gold (IOCG) has developed. Subsequent by the discovery of new deposits of this type, keen interest was attracted worldwide, both from academic institutions and exploration companies (Williams et al., 2005).

Due to its economic importance the relevance of IOCG deposits has been continuously rising among the most important classes of ore deposits and has become a prime target for exploration. The creation of an ultimate exploration model is a big challenge based on complexity and variety of IOCG deposits that may have valuable resources of a wide spectrum of raw materials. They may comprise $\mathrm{Fe}, \mathrm{Cu}, \mathrm{Au}, \mathrm{U}, \mathrm{REE}, \mathrm{F}$, vermiculite and secondary resources of $\mathrm{Ag}, \mathrm{Nb}, \mathrm{P}, \mathrm{Bi}, \mathrm{Co}$. The IOCG deposits are generally characterized by high tonnage and low-grade ore. IOCG deposits play an important role on the global raw-material market (Kolb, Stensgaard, 2009; Sandrin et al., 2009).

\subsection{Utilization of remote sensing for geological mapping}

Mineral type and composition can be inferred and interpreted by studying the position, strength (depth), and shape of their absorption features in the optical electromagnetic spectrum. These spectral signatures in combination with spectral resolution of different image types provide powerful means to discriminate different materials on the earth surface from optical remote sensing data (Matteoli et al., 2010). Since the differences in spectral absorption characteristics of many minerals are subtle, selecting an efficient method to extract the mineral spectral

\footnotetext{
* Corresponding author
} 
features is essential (Han-Bo et al., 2013). Elimination of redundant information and noise by spectral feature extraction may speed up and improve the interpretation. There exist several methods for feature extraction and dimensionality reduction of remote sensing data. Band ratio and Principal Component Analysis (PCA) are widely used techniques in mineral mapping (Crosta, Moore, 1989; Van Der Werff, Van Der Meer, 2016; Abdolmaleki et al., 2018; Chen et al., 2019).

A major drawback of optical remote sensing data in mineral exploration is the lack of depth penetration. Most of the geological fields have poor bedrock exposures due to vegetation and snow cover. Two types of the optical remote sensing data are available: hyperspectral and multispectral. Hyperion is the only hyperspectral data used for geological mapping but not available globally. There are multiple multispectral data available with full global coverage. Sentinel-2 has better spatio-spectral resolution and signal to noise ratio among freely available multispectral data. Usually direct mineral identification and quantification is possible by key absorption feature locations, shapes and depths in the reflectance spectra. These features can be extracted hyperspectral or ultraspectral data more accurately whereas lacking or poorely evident in multispectral data such as Sentinel2. Therefore, mineral mapping using multispectral data (e.g., Sentinel-2) usually performed employing indirect techniques such as data transformation and indexing or feature extraction. Thus Sentinel-2 data integration with other geoscientific data is an important topic to enhance the applicability of remote sensing data in mineral potential mapping.

\section{STUDY AREA AND DATASET}

\subsection{Case study}

Inglefield Land (see Figure 1), northwest Greenland, has been subject to several investigations with the aim of providing data for mineral exploration. Investigations in Inglefield Land were carried out by the Geological Survey of Denmark and Greenland (GEUS) in 1994 (an airborne combined magnetic and electromagnetic GEOTEM survey) and ground follow-up in 1995 (geological mapping, mineralization studies, and geochemical survey). Geological investigations were carried out in Inglefield Land in 1999 by GEUS to complete the 1:500,000 geological map of the national map sheet coverage (Thomassen et al., 2000). A review of geoscientific work carried out in Inglefield Land is included in reports by (Dawes, 1999; Rasmussen et al., 2001). The 1994 geophysical surveying was followed by a detailed aeromagnetic and an airborne gravity survey funded by industry (Rasmussen, 2010). Geochemical data are furthermore available together with results from geological mapping campaigns.

Mineral exploration in Greenland is a challenging task in some cases due to logistical issues related to the large areal extent and transportation, energy supply at remote locations, and weather conditions. The Copernicus data may make exploration more efficient and more focused by identifying areas of specific interest and higher mineral prospectivity.

\subsection{Datasets}

Two tiles (T19XDH and T19XEH) Sentinel-2 L1C satellite data acquired on 31 August 2018 were selected for this study. The Sentinel-2 multispectral mission carries a wide-swath, highspatial resolution sensor.

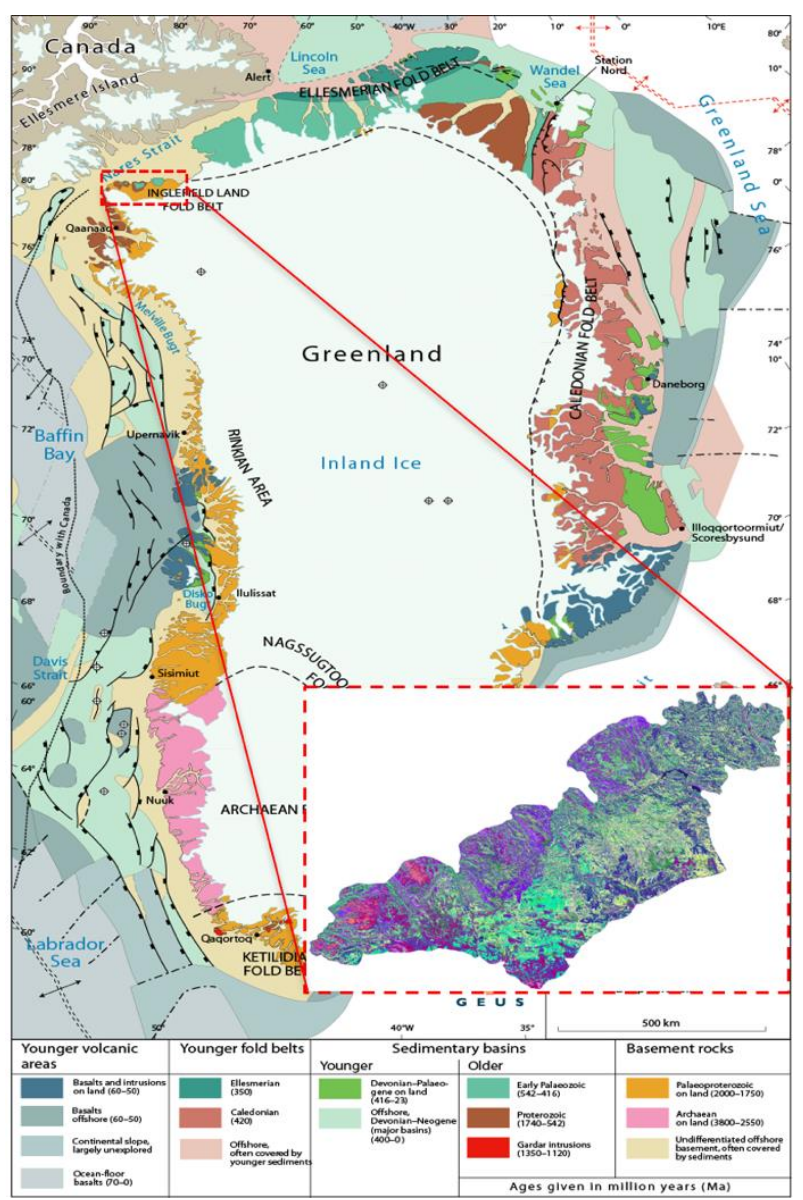

Figure 1. Location of the study area (Inglefield Land) in northwest Greenland. Geological map from Geological Survey of Denmark (GEUS).

It collects 13 spectral bands covering the visible near infrared (VNIR) to the shortwave infrared (SWIR) (433-2190 nm) range of the electromagnetic spectrum (Drusch et al., 2012).

The fact that optical remote sensing data have no depth penetration emphasizes the importance of performing joint interpretation with data providing information at depth, i.e. geophysical data. The data used for integration with Sentinel-2 data are:

- Airborne magnetic data

- Airborne time domain electromagnetic data (GEOTEM)

- Geochemistry from stream sediments and rocks

- Lithology and structural geological data.

\section{RESEARCH APPROACH AND RESULTS}

Figure 2 outlines the general processing flow followed in this study. After implementing the satellite data pre-processing step, which includes radiometric (mainly atmospheric) corrections and resampling, the different processing methods such as feature extraction are applied to the data. Airborne geophysical data (magnetic and electromagnetic), geochemical data (stream sediments and soil) and geological field observation data (outcrops) are transferred into a common geo database in order to prepare for application of data integration techniques. Finally, ground truth information are integrated as validation data on the imagery interpretation. 


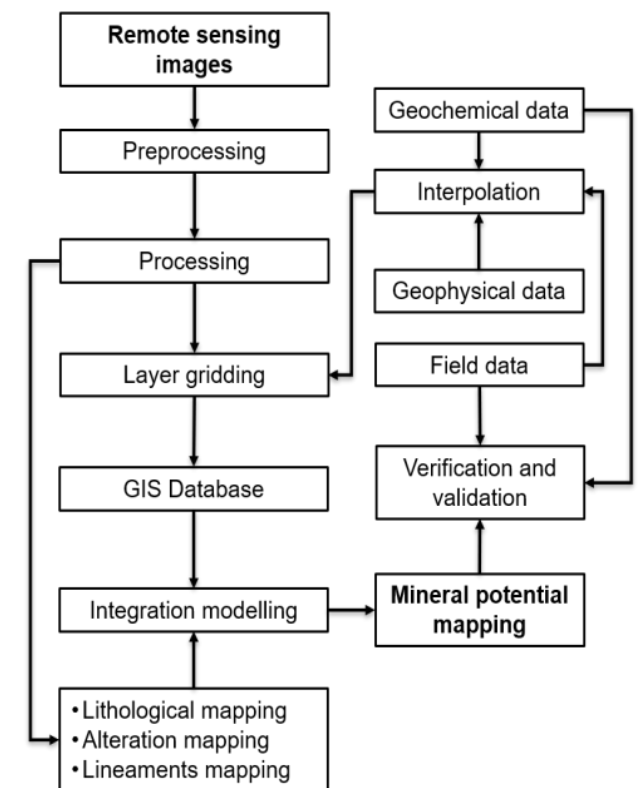

Figure 2. Flow diagram of the applied methodology.

\subsection{Pre processing}

Sen2Cor is a processing tool developed by Telespazio VEGA Deutschland GmbH on behalf of ESA for correcting Sentinel-2 Level-1C Top-Of-Atmosphere (TOA) to a Bottom-OfAtmosphere (BOA) reflectance product. This involves scene classification, an atmospheric correction and a subsequent conversion into Level-2A data (Main-Knorn et al., 2018).

Three different spatial resolutions of 60,20 and $10 \mathrm{~m}$ are used for the original data bands. Data from the bands with $20 \mathrm{~m}$ and $60 \mathrm{~m}$ spatial resolution are resampled to $10 \mathrm{~m}$ by a nearest neighbour interpolation method for use in this study.

\subsection{Processing}

Many pure materials, such as minerals, can be recognized by the position, strength (depth), and shape of their absorption features. The goal of feature extraction is to reduce the data space dimensions without loss of significant information. These reduced data will then allow for the separation of different spectra through classification (Abdolmaleki et al., 2018). There are several feature extraction methods which have proved particularly useful in the classification of remote sensing images. In this project there is focus on band ratio and PCA to produce the maps based on the spectral absorption feature of altered minerals.

3.2.1 Band ratios: Band ratio is a technique in which the digital numbers (DNs, brightness values) of one band are divided by the digital numbers of another band. The choice of ratios is based on the peaks and troughs of a reflectance curve. Usually, the band with higher reflectance is divided by a band with low reflectance.

Band ratios serve as proxies for mineral assemblages or individual mineral groups. A summary with proposed band ratio and indices for Landsat 5 TM, ASTER, Landsat 8 OLI Sentinel2A MSI can be found in (Van Der Werff, Van Der Meer, 2016).

Figure 3 shows the band ratio map $4 / 2$ for iron oxide alteration and $11 / 12$ for hydroxyls alteration.
3.2.2 Principal Component Analysis (PCA): PCA is a multivariate statistical technique used to enhance and separate certain types of spectral signatures from the background. By applying a linear transformation, this technique reduces the redundancy of correlated data and transforms a set of correlated input bands into uncorrelated principal components (PCs).
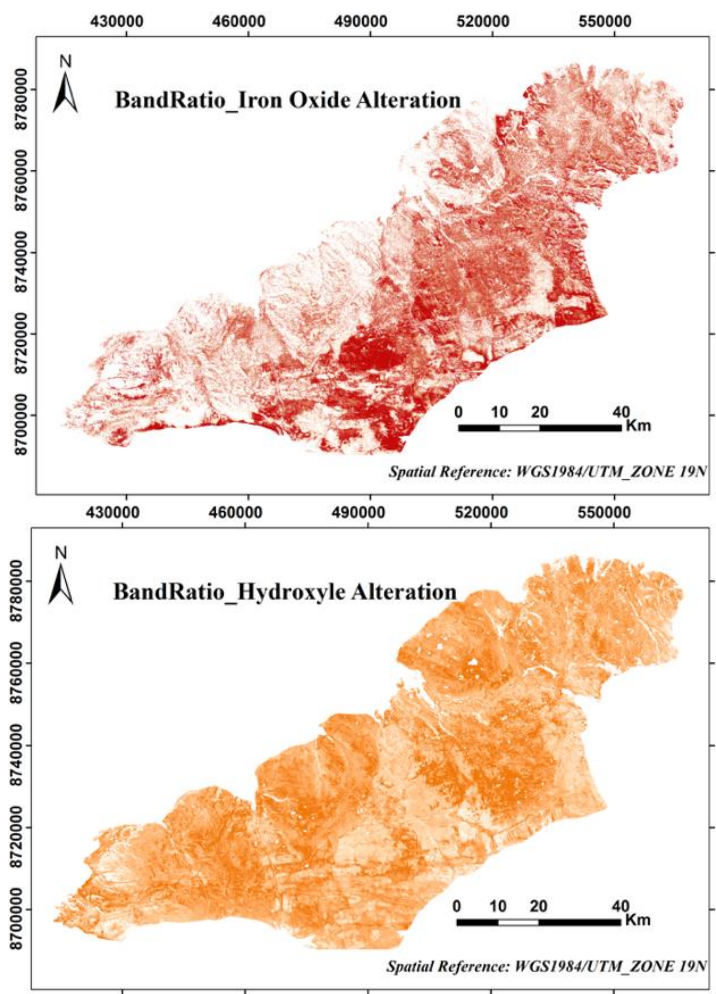

Figure 3. $\mathrm{FeO}$ and $\mathrm{OH}$ alteration maps based on band ratio techniques; pixels with high colour intensity mark target areas.
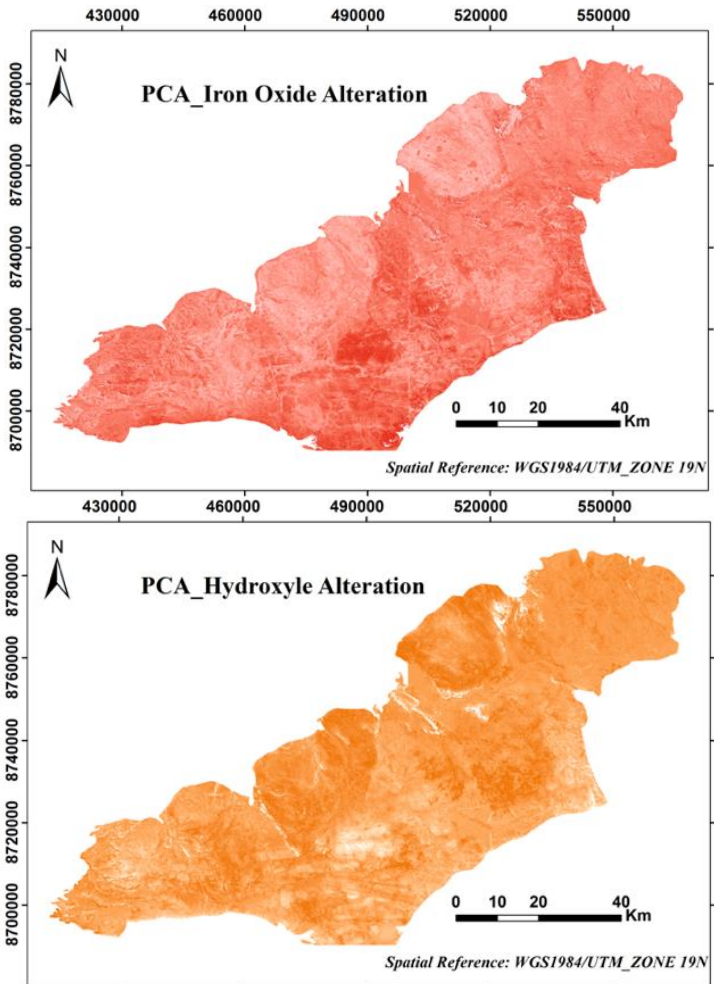

Figure 4. $\mathrm{FeO}$ and $\mathrm{OH}$ alteration Maps based on PCA technique; pixels with high colour intensity mark target areas. 
The magnitude of the associated eigenvalues provides information, although non-unique, about the composition and distribution the surface material (Laughlin, 1991; Dolati, EslamBonyad, 2016; Abdolmaleki et al., 2018).

Figure 4 shows the result of the PCA for mapping iron oxide (bands 3, 6, 8a, and 11) and hydroxyls alterations (bands 3, 8, 11, and 12) of the study area. In both cases, PC4 shows the potential areas (Chen et al., 2019).

3.2.3 Lineaments: Spatial features in images are often used as indicators of geological surface structures. The brightness contrast and pattern of satellite image are used to display lineaments and folds of the study area. In this study the directional filters have been applied on the PC1 eigenvalues of the PCA. Lineaments generated from images using directional filters are shown in Figure 5.

\subsection{Classification}

Image classification methods can be divided generally into two types, supervised and unsupervised. Supervised classifiers use image pixels representing regions of known features as training samples. Unsupervised classifiers identify groups of pixels that exhibit a similar spectral response without the need to specify a training area. Self-Organizing Maps (SOM) as unsupervised classifier and Support Vectors Machine (SVM) as supervised classifier are selected for discrimination lithological and structural units from the Sentinel-2 image of the study area.

3.3.1 Self-Organizing Map (SOM): The SOM is a vector quantization method which places the prototype vectors on a regular low-dimensional grid in an ordered fashion. A SOM consists of neurons organized in a low dimensional grid; each neuron is a d-dimensional weight vector where $\mathrm{d}$ is equal to the dimension of the input vectors. The neurons are connected to adjacent neurons by a neighborhood relation, which dictates the topology, or structure, of the map (Kohonen, 1982; Vasanto et al., 1999).

The SOM processing finds an approximation to the data by mapping the normalized input data into another data set with fewer data than the initial amount of data. This approximation referred to as the best matching units (BMU) has the same amount of data types (same dimensionality) as the input data. Data normalization is performed by subtracting the mean and subsequent division with the data standard deviation. The BMU's are presented in the SOM, which is a two-dimensional map, and referred as the SOM space. Each of the input data has an associated BMU to which the data are most similar to (Kohonen, 1982).

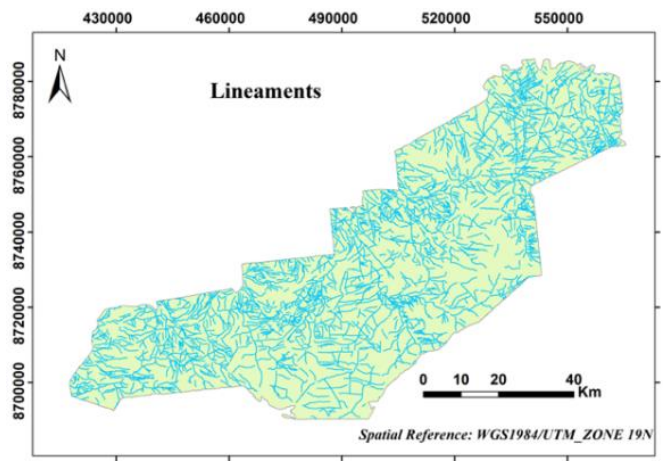

Figure 5. Lineaments based from applying directional filters to remote sensing data.

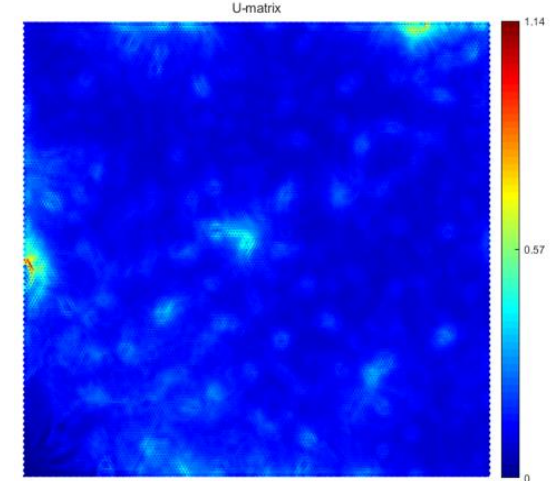

Figure 6. U-matrix presentation in SOM for one Sentinel 2 tile of the study area.

Several input data may be associated with the same BMU in which case the SOM presentation may be viewed as a data reduction of the input data.

The U-matrix (Figure 6) describes the deviation for a particular cell to the adjacent surrounding cells by using a color representation of the average "distance" between the BMU's. The darker blue colors represent small distances and indicate similarity whereas red color show large distances and thereby dissimilarity. Group of green and red segments appear in different places in Figure 6 and indicate that the network has organized the data into diverse clusters. The BMU's are analyzed further with respect to clustering of data. A standard k-means clustering procedure is used. Figure 7 shows the final clustered map of the study area based on SOM algorithm. A total of $15 \mathrm{k}$ mean clusters where selected based on analysis of the DaviesBuildin index. A comparison of each cluster with known geological lithology observations from the study area provides a key for lithology classification and prediction.

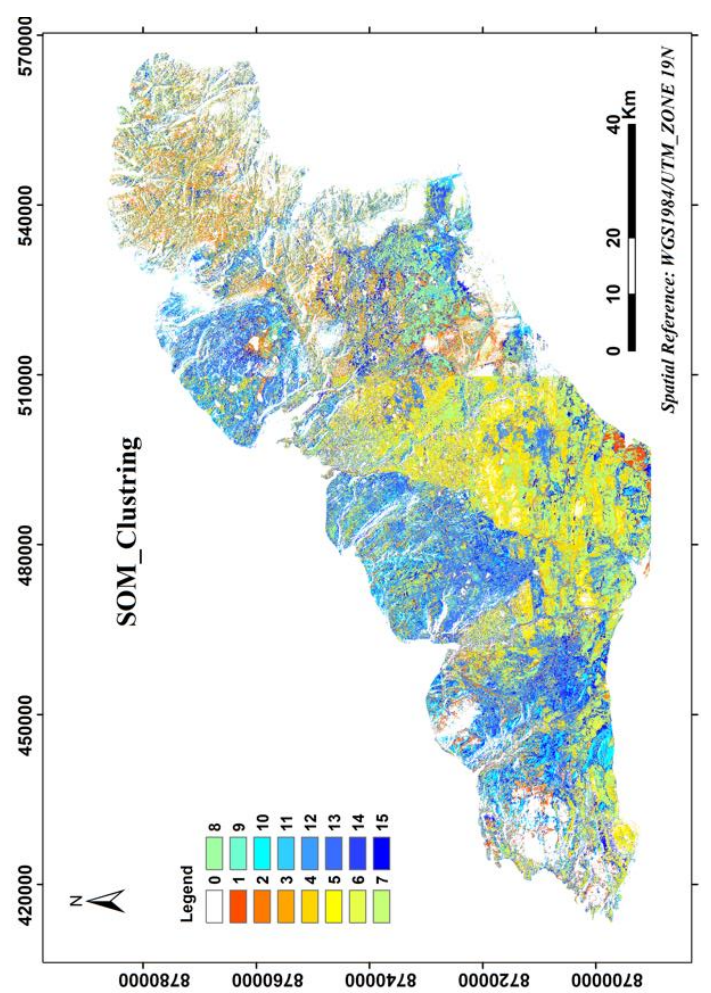

Figure 7. SOM clustering of the Inglefield Land Sentinel-2 data. Locations covered by snow have been masked (white colour). 


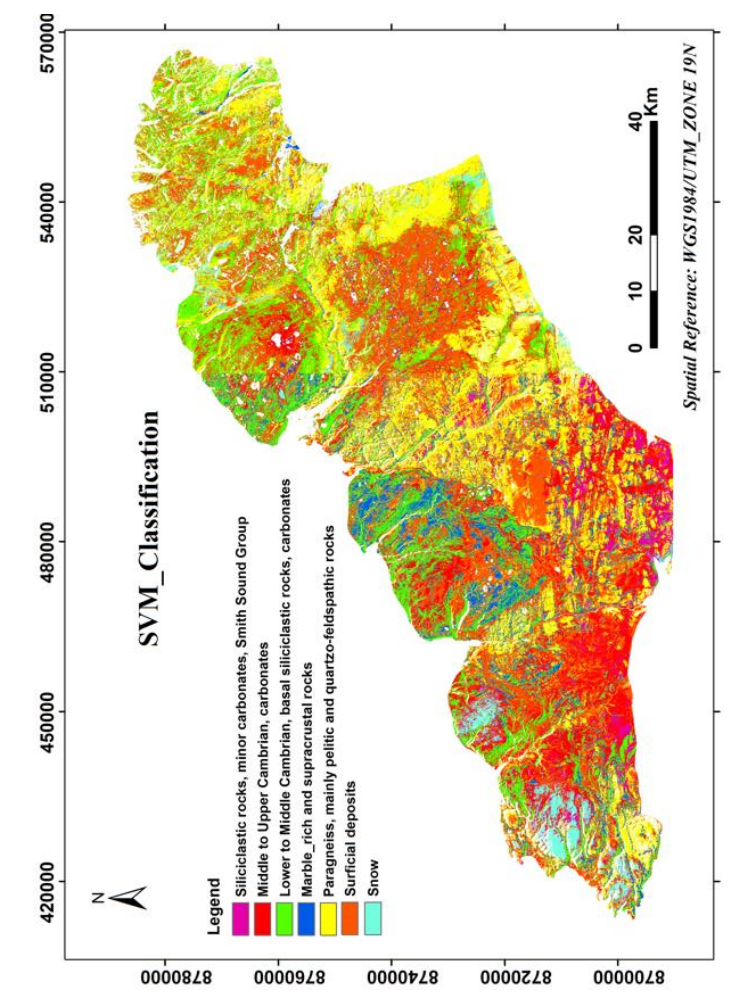

Figure 8. SVM classification of the Inglefield Land Sentinel-2 data.

3.3.2 Support Vector Machine (SVM): SVM is one of the most commonly used classifiers for remote sensing multi-band images. The support vectors (SVs) employ an optimal hyperplane with a maximizing distance between the classes' closest points. Support vectors are lying on the boundaries of the training samples that give the maximum margin between the two classes and place a separating linear hyperplane between them. One of the advantages of SVM is that it requires a small training sample size compared to the conventional classifiers (Ghezelbash et al., 2019).

The training samples for the SVM classifier have been selected based on reports of the Inglefield Land geology prepared by GEUS (Thomassen et al., 2000). Figure 8 illustrates the SVM based lithological classification using Sentinel-2 images of the study area.

\subsection{Data integration}

Data integration is in general acknowledged as a key parameter for successful and optimised exploration. The fact that Sentinel data has no depth penetration furthermore emphasizes the importance of performing joint interpretation with data providing information at depth.

One of the main steps in mineral exploration is to determine prospective areas in a particular region. In this manner various thematic (e.g., geological, geophysical, geochemical) map are integrated for producing a mineral prospectivity map or mineral favorability map. Integration of Copernicus remote sensing data with geophysical data are in focus for this study.

3.4.1 Fuzzy Analytic Hierarchy Process: Fuzzy Analytic Hierarchy Process (FAHP) is a popular and widely used method for multi-criteria decision making. FAHP is a hybrid data integraton technique based on fuzzy logic and weights of input layers.

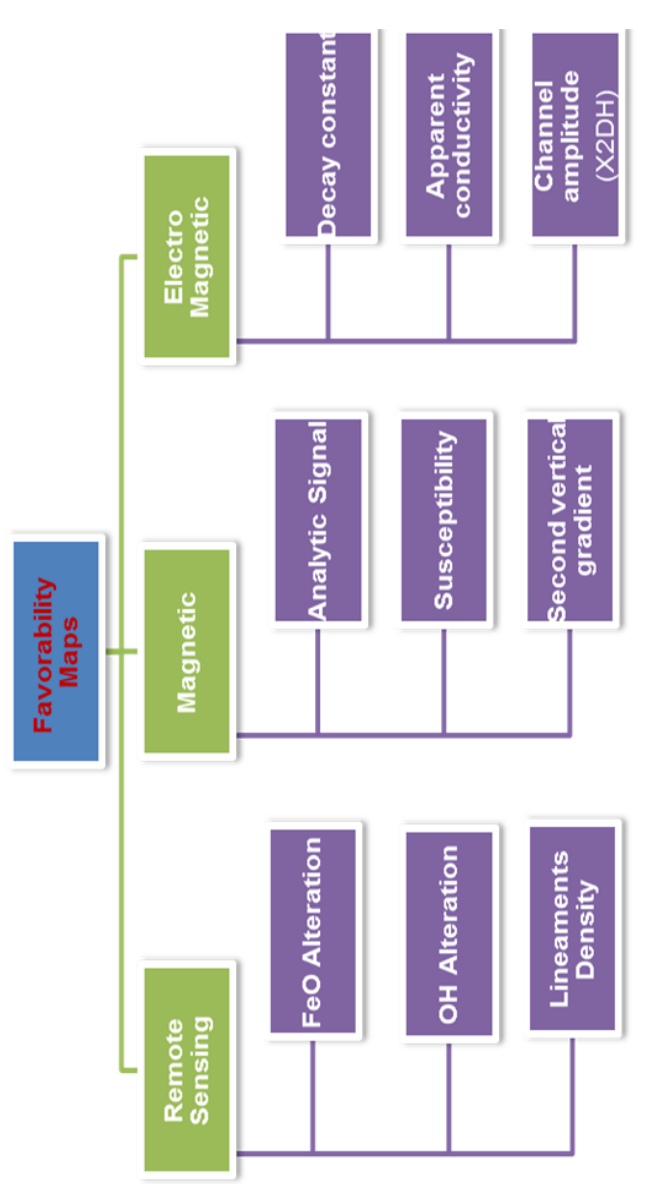

Figure 9. Flow diagram of input layers with respect to data type.

We have used the above technique to calculate the mineral favorability map.

The FAHP is based on mainly three principles, namely:

- Construction of a hierarchy

- $\quad$ Priority setting

- Logical consistency

It should be noted that the quality of the results of the FAHP is strictly related to the consistency of the pairwise comparative judgments. Logical consistency can be evaluated based on calculated consistency ratios (CR). More information about the FAHP can be found in Abedi et al. (2013) and Karimi et al. (2011).

The steps of applying FAHP in this project are:

- Nine input layers (Figure 9) are derived from three data types: remote sensing, airborne magnetic and electromagnetic.

The iron oxide and hydroxide alteration maps and lineament density map were extracted using remote sensing data and are shown in Figure 10. Six layers of geophysical data are used as input. Three (analytic signal, apparent susceptibility, second order vertical derivative) are derived from airborne magnetic total field data (Figure 11). Three (time decay constant, apparent conductivity, channel 12 amplitude) are derived from the airborne GEOTEM electromagnetic data (Figure 12).

- Pairwise comparison matrices were constructed using inputs from three decision makers (DM) with expertise in mineral exploration (Table 1). 
- Calculated consistency ratios obtained from pairwise comparison matrices were less than 0.1 .

- Fuzzy evaluation matrices with respect to all three data types were made.

- Weights of the nine evidential layers were determined.

- The evidential layers are integrated by fuzzy operators (Fuzzy sum for evidential layers)

- The calculated weights were multiplied to the corresponding evidence layers.

Finally, the fuzzy gamma operator (gamma $=0.9$ ) is used to integrate maps of remote sensing, airborne magnetic and airborne electromagnetic data types in order to construct the final favorability map (Figure 13).

- Validation of the favorability maps was performed using geochemical and geological field information.

\begin{tabular}{|c|c|c|c|}
\hline DM1 & FeO & OH & Lineaments \\
\hline FeO & 1 & 3 & 2 \\
\hline OH & 0.33 & 1 & 0.5 \\
\hline Lineaments & 0.5 & 2 & 1 \\
\hline DM2 & FeO & OH & Lineaments \\
\hline Feo & 1 & 1 & 2 \\
\hline OH & 1 & 1 & 2 \\
\hline Lineaments & 0.5 & 0.5 & 1 \\
\hline DM3 & FeO & OH & Lineaments \\
\hline FeO & 1 & 1 & 2 \\
\hline OH & 1 & 1 & 1 \\
\hline Lineaments & 0.5 & 1 & 1 \\
\hline
\end{tabular}

Table 1. Pairwise comparison matrices for evidential layers of remote sensing criteria.

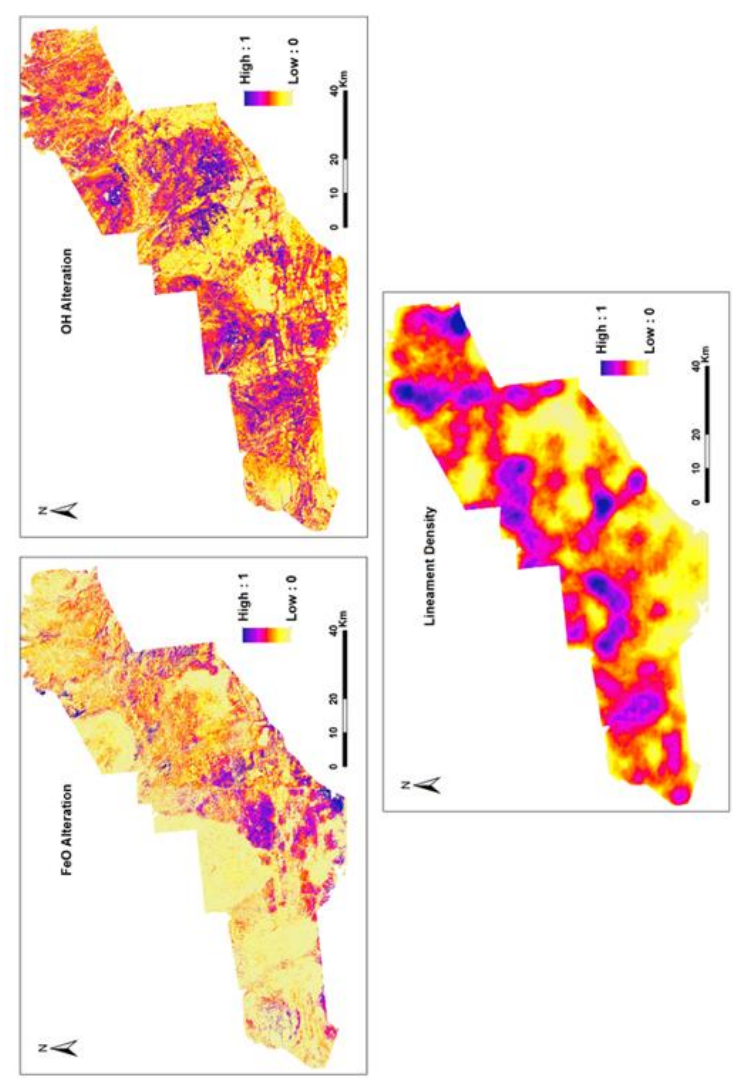

Figure 10. Evidential layers from remote sensing data.

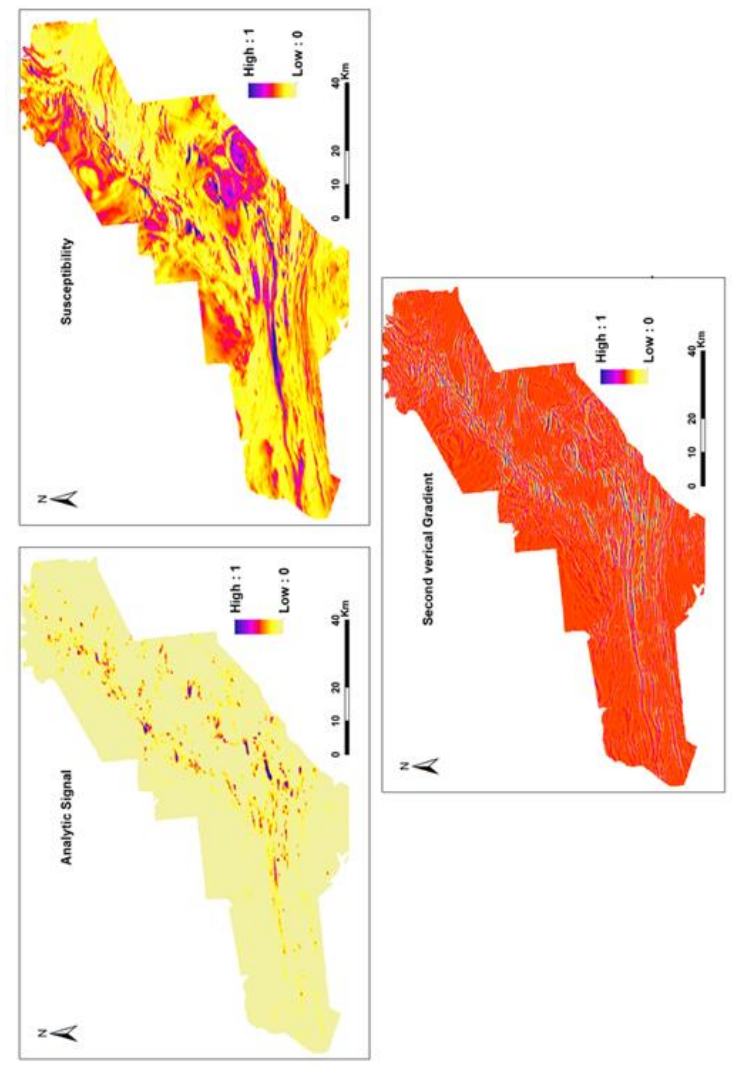

Figure 11. Evidential layers from magnetic data.

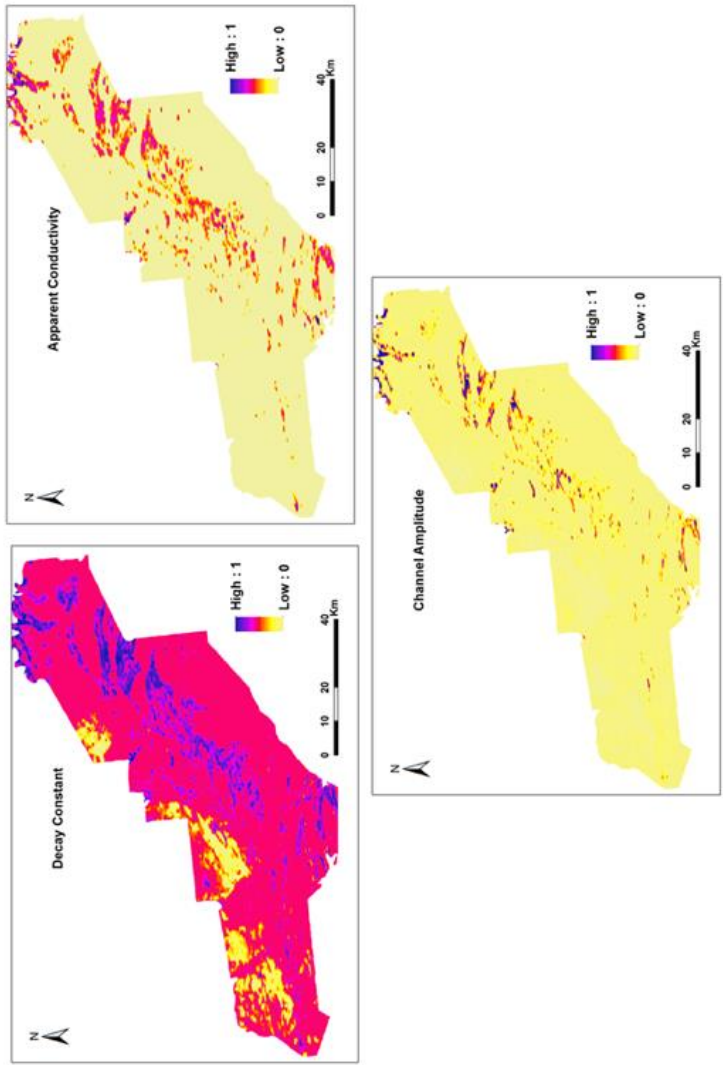

Figure 12. Evidential layers from electromagnetic data. 


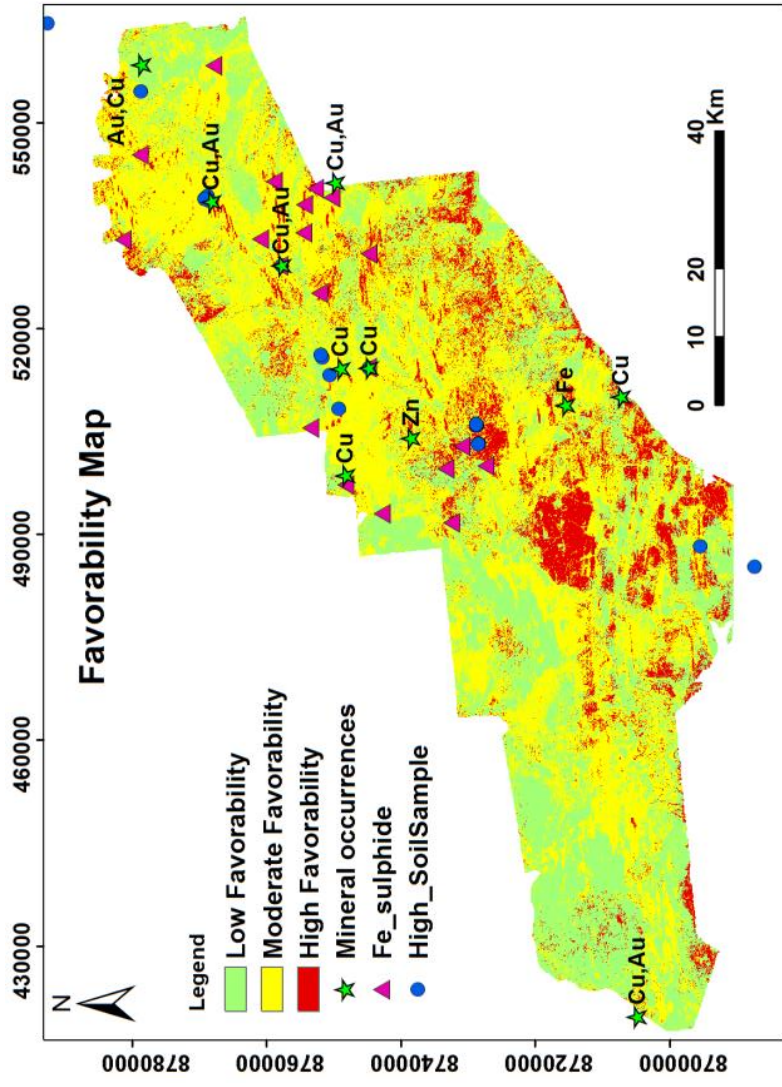

Figure 13. Favorability map based on applying the FAHP technique in the Inglefield Land.

\section{DISCUSSION AND CONCLUSION}

The results from the SOM and SVM classifiers are not directly comparable due to e.g. differences in the number of clusters, use of training samples in SVM and also differences in the approaches. Nevertheless, a good agreement in terms of class pattern coverage is evident. Additionally, a good agreement with the lithological map of the study is noted.

Figure 13 shows the favorability map together with previously mapped mineral occurrences, mapped high concentrations of $\mathrm{Fe}$ sulfide from soil samples collected in the study area. A significant correlation is noted between the occurrences of mineralization and high favorability. However, large areas are marked as highly favorable but without known occurrences. Several reasons may explain this apparent discrepancy: lack of detailed ground geological observations, lack of detailed soil and rock sampling with geochemical analysis, poor bedrock exposures and a glacial depositional environment. In particular, the geophysical data provide information at depth that are not necessarily exposed. Optical remote sensing data provides only surface information and a good correlation between ground observation information should be expected.

Based on previous stream sediment sampling and results of geological surveying, we conclude that the Sentinel-2 data are providing information applicable for IOCG exploration. The integration of remote sensing and processed airborne geophysical data by utilizing various correlation analyses techniques provide results that highlights areas of particular interest for ground follow-up in exploration. The results allow a more focused fieldwork and thereby planning of a cost-efficient field campaign.

\section{ACKNOWLEDGEMENT}

The Geological Survey of Denmark and Greenland (GEUS) is acknowledged for providing the data for this study. This work was funded by the European Union's Copernicus (RawMATCop) Programme 2018-2020, Grant Agreement No.: 271/G/GRO/COPE/17/10036. The support from the EU and EIT RawMaterials GmnH is highly appreciated.

\section{REFERENCES}

Abdolmaleki, M., Fathianpour, N., Tabaei, M; 2018: Evaluating the performance of the wavelet transform in extracting spectral alteration features from hyperspectral images. International journal of remote sensing, 39(19), 6076-6094.

Abedi, M., Torabi, S.A., Norouzi, G.H., 2013: Application of fuzzy AHP method to integrate geophysical data in a prospect scale, a case study: Seridune copper deposit. Bollettino di Geofisica Teorica ed Applicata 54(2).

Chen, L., Yang, X., Zhen, G., 2019: Potential of Sentinel-2 data for alteration extraction in coal-bed methane reservoirs. Ore Geology Reviews 108, 134-146.

Crosta, A.P., Moore, J.M., 1989. Enhancement of Landsat Thematic Mapper imagery for residual soil mapping in SW Minais Gerais State, Brazil: A prospecting case history in Greenstone belt terrain. In: Proceedings of the 7th ERIM Thematic Conference: Remote sensing for exploration geology, $1173-1187$.

Dawes, P. R., 1999: A review of geoscientific exploration and geology in the Kane Basin region of Greenland, central Nares Strait. GEUS, Geological Survey of Denmark and Greenland, Denmark.

Dolati, M. K., EslamBonyad. A., 2016: Use of Principal Component Analysis in Accuracy of Classification Maps (Case Study: North of Iran). Researcher Journal Forest 10 , 23-29.

Drusch, M., Del Bello, U., Carlier, S., Colin, O., Fernandez, V., Gascon, F., Hoersch, B., Isola, C., Laberinti, P. Martimort, P., Meygret, A., Spoto, F., Sy, O., Marchese, F., Bargellini, P., 2012: Sentinel-2: ESA's optical high-resolution mission for GMES operational services. Remote Sens. Environ., 120, pp. 25-36, doi.org/10.1016/j.rse.2011.11.026

Ghezelbash, R., Maghsoudi, A., Carranza, E. J. M., 2019: Performance evaluation of RBF-and SVM-based machine learning algorithms for predictive mineral prospectivity modeling: integration of SA multifractal model and mineralization controls. Earth Science Informatics, 12(3), 277293.

Han-Bo, L., Z. Ying-Jun., Z. Dong-Hui., P. Wei., 2013: A Method Based on Wavelet Transform for Mineral Spectral Characteristics Extraction. Advanced Materials Research 718, 617-620.

Karimi, A.R., Mehrdadi, N., Hashemian, S.J., Nabi-Bidhendi, G.R., Tavakkoli-Moghaddam, R., 2011: Using of the fuzzy topsis and fuzzy ahp methods for wastewater treatment process selection. International journal of academic research, 3(1).

Kohonen, Teuvo (1982). "Self-Organized Formation of Topologically Correct Feature Maps". Biological Cybernetics. 43 (1): 59-69. doi:10.1007/bf00337288 
Kolb, J., Stensgaard, B. M., 2009: Iron oxide copper gold mineralising systems in Greenland. Geology and Ore 13, 1-12. Geological Survey of Denmark and Greenland. ISSN1602-818x.

Laughlin, W.P., 1991: Principal Component Analysis for Alteration Mapping. Photogrammetric Engineering \& Remote Sensing, 57, 9, pp. 1163-1169.

Main-Knorn, M., Pflug, B., Louis, J., Debaecker, V., MüllerWilm, U., Gascon, F., 2018. Sen2Cor for Sentinel-2, Image and Signal Processing for Remote Sensing, Conference 2017. DOI: $10.1117 / 12.2278218$

Matteoli, S., Diani, M., Corsini, G., 2010: A tutorial overview of anomaly detection in hyperspectral images. IEEE Aerosp. Electron. Syst. Mag 25, 5-28.

Rasmussen, T.M., Thorning, L., Stemp, R.W., Jørgensen, M.S., Schjøth, F., 2001: AEM Greenland 1994-1998 - summary report. Danmarks og Grønlands Geologiske Undersøgelse Rapport 2001/58, 46 pp. + 1 CD-ROM.

Rasmussen, T.M, 2010: Evaluation and modelling of geophysical data from Inglefield Land with emphasis on the Minturn magnetic anomaly. Report prepared for NunaMinerals A/S. Danmarks og Grønlands Geologiske Undersøgelse Rapport 2010/111. 80 pp, 3 Appendices.

Sandrin, A., Edfelt, Å., Waight, T. E., Berggren, R., Elming, S. $\AA$ A., 2009: Physical properties and petrologic description of rock samples from an IOCG mineralized area in the northern Fennoscandian Shield, Sweden. Journal of Geochemical Exploration 103(2-3), 80-96.

Thomassen, B., Pirajno, F., Iannelli, T. R., Dawes, P. R., Jensen, S. M., 2000: Economic geology investigations in Inglefield Land, North-West Greenland: part of the project Kane Basin 1999. Danmarks og Grønlands Geologiske Undersøgelse Rapport 100(98), 42.

Van Der Werff, H., Van Der Meer, F., 2016: Sentinel-2A MSI and Landsat 8 OLI provide data continuity for geological remote sensing. Remote sensing 8(11). P 883

Vasanto, J., Himberg,J., Alhoniemi,E., 1999. Self-organizing map in Matlab: the SOM Toolbox. In Proceedings of the Matlab DSP Conference 1999 Nov 16, Espoo, Finland, 99, 16-17.

Williams, P.J., Barton,M.D., Johnson, D.A., Fontbote, L., de Haller, A.,Mark, G., Oliver, N.H.S.,Marschik, R., 2005: Iron oxide copper-gold deposits: geology, space-time distribution, and possible modes of origin. Econ. Geol. 100, 371-405. 